\title{
Evolution, Culture, and Care for Betta splendens ${ }^{1}$
}

\section{Craig Watson, Matthew DiMaggio, Jeffrey Hill, Quenton Tuckett, and Roy Yanong ${ }^{2}$}

The commercial betta, or Siamese fighting fish (Betta splendens), is one of a group of fishes called the anabantoids (suborder Anabantoidei), most of which occur in fresh waters of Africa and southern Asia. There are roughly 137 labyrinth fishes in three families, Anabantidae (28 species), Helostomatidae (1 species), and Osphronemidae (108 species including $B$. splendens). The anabantoids are also known as labyrinth fishes, which, unlike most other fishes, often do not rely primarily on the gills for respiration. The gills of labyrinth fishes are relatively small and primarily excrete the waste products ammonia and carbon dioxide. In fact, many labyrinth fishes are obligate air breathers, meaning they must breathe at the surface to survive. Other fishes have evolved a number of solutions to allow them to breathe air, including lungs and modifications to their gut and skin. Labyrinth fishes take their name from a specialized air-breathing structure called the labyrinth organ. Labyrinth fishes have paired chambers located above the gills which are extensions of the first gill arch. These chambers contain complex, folded, bony structures covered with respiratory epithelium (the labyrinth organ), allowing them to breathe air.

Labyrinth fishes are well adapted to their environment. However, some environments, including those that have higher temperatures and lower dissolved oxygen levels, whether continuous or seasonal, are suboptimal for many fishes, affecting respiration via the gills and also the development of young. These environments are thought to have shaped the evolution of labyrinth fishes, a group that formed $\sim 60$ million years ago. Life in hypoxic environments appears to have been the driving force behind the evolutionary diversification of labyrinth fishes, including the genus Betta, the most diverse group within the family Osphronemidae with over 73 species. A variety of behavioral, morphological, and physiological traits evolved in response to development of air breathing as an adaptation to living in a hypoxic environment. While the labyrinth organ may be one of the most obvious traits, others, such as bubble nest building for reproduction, are also associated with this adaptation. The bubble nest allows eggs to develop in environments with elevated temperature and low $\mathrm{pH}$ and dissolved oxygen, relatively free of predators. Placement of the eggs at the surface increases oxygen exchange, while the bubble nest also prevents the eggs from drying. One other notable aspect of this evolution is the aggressive nature of many labyrinth fish, especially of males defending their nests. betta males are among the most aggressive, one reason they have become such a favorite in the hobby.

The betta, native to Southeast Asia, is one of the most popular aquarium species because of its hardiness, beautiful, bold colors, and long fins developed by selective breeding in captivity. In the wild, the betta is typically found in standing waters, including shallow ponds, rice paddy fields, and even puddles. Compared to the conspicuous color patterns observed in captivity, the wild betta is dull brown or green. In April and May, during the breeding season in Thailand,

1. This document is FA212, one of a series of the School of Forest Resources and Conservation, Program in Fisheries and Aquatic Sciences, UF/ IFAS Extension. Original publication date March 2019. Visit the EDIS website at https://edis.ifas.ufl.edu for the currently supported version of this publication.

2. Craig Watson, director; Matthew DiMaggio, assistant professor and Extension specialist; Jeffrey Hill, associate professor and Extension specialist; Quenton Tuckett, research assistant scientist; and Roy Yanong, professor and Extension veterinarian; Tropical Aquaculture Laboratory, Program in Fisheries and Aquatic Sciences, School of Forest Resources and Conservation, UF/IFAS Extension, 1408 24th St SE, Ruskin, FL 33570.

The Institute of Food and Agricultural Sciences (IFAS) is an Equal Opportunity Institution authorized to provide research, educational information and other services only to individuals and institutions that function with non-discrimination with respect to race, creed, color, religion, age, disability, sex, sexual orientation, marital status, national origin, political opinions or affiliations. For more information on obtaining other UF/IFAS Extension publications, contact your county's UF/IFAS Extension office. 
the betta will move to shallow water edges to breed. Specific habitat characteristics for a betta population in Thailand are $\mathrm{pH}$ of 5.47 (range from approximately 5.28 to approximately 5.80 ), temperature of $29.9^{\circ} \mathrm{C}$ (about $86^{\circ} \mathrm{F}$ on average; range from approximately 27.0 to approximately $31.5^{\circ} \mathrm{C}$ ), and depth of about $5.0 \mathrm{~cm}(2$ inches on average, range from approximately 2.0 to approximately $9.4 \mathrm{~cm}$ ). In particular, dissolved oxygen can be low (average about $3.8 \mathrm{mg} / \mathrm{L}$ ), exhibiting extreme variation (dissolved oxygen ranges from 0.0 to about $7.4 \mathrm{mg} / \mathrm{L}$ ), typical of daily cycles of dissolved oxygen in some tropical environments. Bettas were also found at relatively low density, just 1.7 individuals per square meter (range $=0.5$ to 4.8 individuals per square meter), and the sex ratio was skewed towards females with 1.4 females for each male. Overall, these habitats were characterized by heavy emergent vegetation, shallow water, low dissolved oxygen, high temperature, and an acidic $\mathrm{pH}$.

The modern betta is a product of almost 100 years of selective breeding. Early on, males were selected for their aggression because fights between two males were popular in Thailand for gambling. Males will almost immediately display aggressive behaviors - spreading their fins and flaring out their gill covers-when they encounter another male. As aggression proceeds, the fish will then bite each other, particularly on the fins and flanks. Males were placed into small containers together to fight, and the first fish to retreat was deemed the loser. In light of the cultural significance of this species, the National Identity Committee of Thailand recently designated the betta as the national aquatic animal.

Today's commercial bettas are much different than these early "fighting" fish, and have now been selected for bright colors as well as elaborate fins because the ornamental hobby is now the main market for this species. Directed breeding efforts today are entirely focused on the beauty of the animal, although male aggression remains.

\section{Culture}

Southeast Asia is responsible for the majority of commercial culture globally. Breeding takes place in small containers (3.78-18.90 liters). A single male and female are placed into the container, which contains floating vegetation and/ or a small piece of Styrofoam in which the male builds the bubble nest. Spawning typically occurs within 1-3 days. The male will wrap his body around the female and fertilize the eggs as she releases them, a few at a time. The male will then pick up the eggs in his mouth as they fall through the water and place them in the bubble nest, with about 300 eggs released per spawning event. When spawning is completed, the female is removed. Males will tend to the fertilized eggs and add bubbles to the nest when needed. Additionally, males will tend to newly hatched larval bettas and make sure they stay in the nest.

Once the larval fish have absorbed their yolk sacs (about 3 days post hatch), they are removed from the spawning tanks and placed into grow-out tanks. They are initially fed live feeds of infusoria (a mixture of very small aquatic organisms) and brine shrimp nauplii (Artemia) and transitioned to commercially available flake or pelleted feeds as they grow. Bettas are reared together as a group until they reach 3 to 4 months old, at which point the males become distinguishable from females and must be separated into individual containers to avoid damage due to aggression. Females are reared in communal tanks.

Individual males are grown commercially in small bottles, primarily half-pint liquor flasks. These bottles are tightly packed next to each other on the ground, allowing workers to walk across the top of the bottles. A small opening is cut in the "shoulder" of each bottle to allow for water to exit. To change the water, water is added to the top of the bottle. Feed is added to each bottle once a day. Male bettas are grown in these conditions for 8 to 12 weeks depending on attributes such as size and finnage desired by hobbyists.

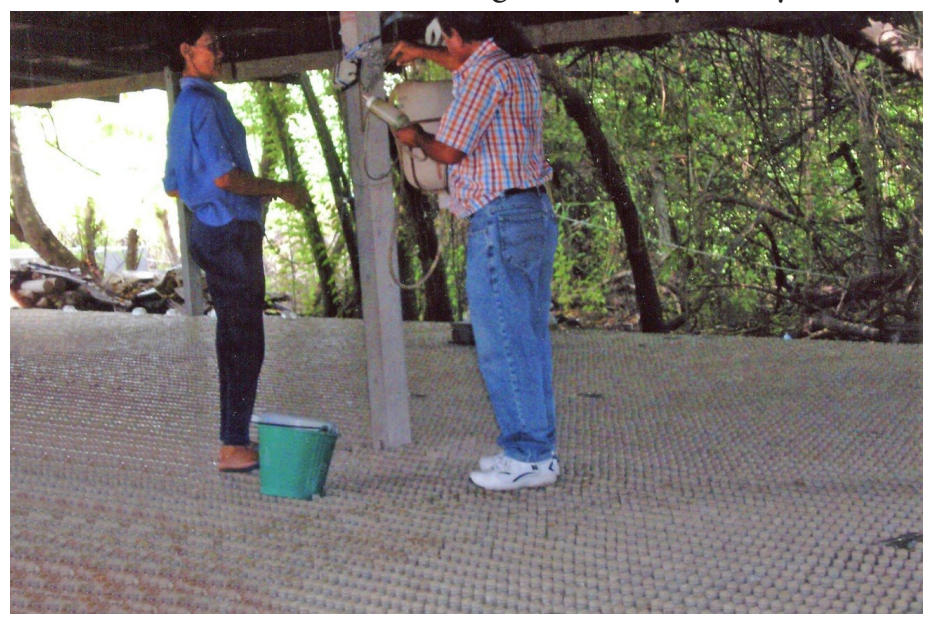

Figure 1. Commercial betta farm in Thailand. The people are standing on half-pint liquor bottles for male grow-out.

Credits: Sandy Moore

To harvest the bettas, the bottles are emptied into a large net where the fish are kept wet but not allowed to swim and thus damage each other. Workers quickly scoop solitary males into individual cups to prepare them for packaging and shipping. Females are counted and placed into communal tanks in preparation for shipping.

Male bettas are placed into small, individual bags for shipping, with just enough water to keep them submerged. Ninety percent of the bag's volume is reserved for air to 
allow the betta enough oxygen to breath during shipment. An estimated 100,000 plus male bettas are shipped weekly via air freight, primarily from Thailand, with destinations throughout the globe. Air freight is priced on the weight of each box, so keeping the water volume to a minimum is essential to supplying hobbyists with an affordable fish. Once received by the importer, male bettas are placed in new bags or small containers with clean water to temporarily hold them before they are distributed to retailers. Data from a major wholesaler in Florida shows less than 2\% mortality for imported bettas during shipment, and less than $0.5 \%$ mortality to the retail market. At the retail level, male bettas are typically kept in small plastic cups either on a shelf or floating in aquariums. As discussed, bettas have evolved to survive in conditions similar to their shipping and holding environments.

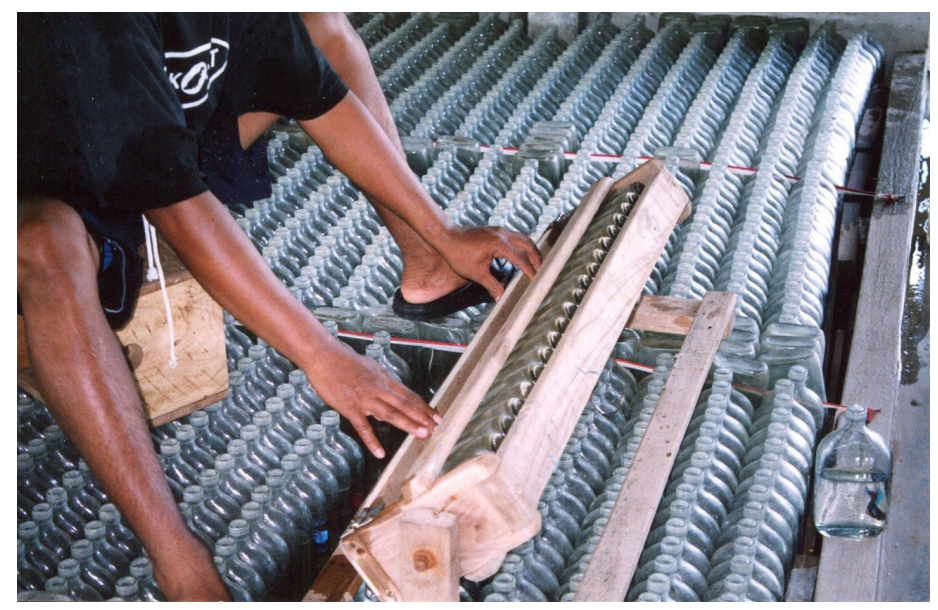

Figure 2. Racks of half-pint liquor bottles used for male grow-out on betta farm in Thailand.

Credits: Sandy Moore

Despite confusing recommendations in the scientific and hobbyist literature, male bettas thrive in small containers as long as water quality, nutrition, and other health management considerations are properly managed. A published research study from Thailand showed that male bettas actually grew better when held in $150 \mathrm{ml}$ of water compared to $300 \mathrm{ml}$ of water. Given their adaptation to survive and reproduce in shallow, warmer, low-oxygenated water, as well as the commercial production conditions they are grown in, the domestic male betta is well suited to the small aquaria and "bowls" in which they are commonly housed.

Bettas, like all other fish, are susceptible to disease. Good water quality, nutrition, and biosecurity will help prevent disease and promote good health (see Stress-Its Role in Fish Disease https://edis.ifas.ufl.edu/fa005). If a disease outbreak does occur, proper diagnostics, including working with a fish veterinarian, will be key to successful management.

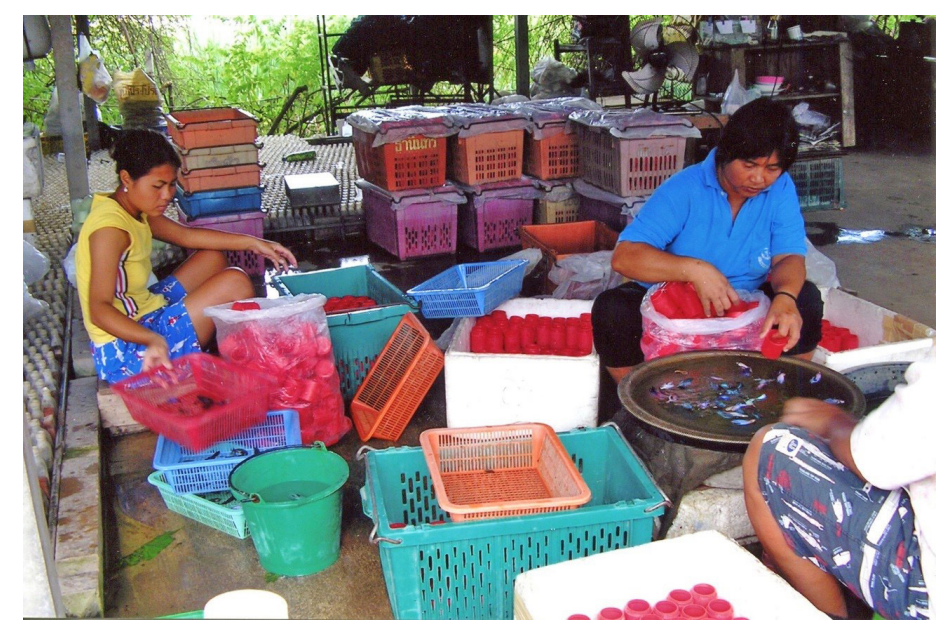

Figure 3. Harvesting male bettas on a commercial farm in Thailand. Credits: Sandy Moore

Water quality is a critical consideration for ensuring the health and longevity of aquarium fish. However, water quality is not dependent on the size of the container, but rather on management and husbandry. Bettas prefer calm water as shown by research using flow as a stressor, so heavy filtration may actually be harmful to a betta's health and welfare. Aquariums of limited volume and reduced filtration should be managed to include frequent water changes so that uneaten feed as well as ammonia and other dissolved wastes are not allowed to reach harmful levels (See Ammonia in Aquatic Systems https://edis.ifas.ufl.edu/ fa031). As mentioned, bettas thrive in warmer water and do not do well in cold water. If they are kept in an unfiltered, unheated container, the air temperature of the room should be maintained at no less than $22^{\circ} \mathrm{C}\left(71.6^{\circ} \mathrm{F}\right)$.

Betta nutrition in aquaculture is fairly simple and varies according to age of the fish. Larval (newly hatched and very young) bettas are initially offered small live feed organisms such as brine shrimp nauplii, microworms (Panagrellus redivivus), ciliates, Moina etc. These organisms are preferred at first feeding because they are the appropriate size for ingestion by the fish, and they elicit an active feeding response. As the larvae grow they can be gradually weaned onto commercially available diets. These "dry diets" are preferred to live feeds because there is less labor associated with their use, and they can be obtained easily and consistently. Grow-out diets should contain at least $35 \%$ protein to promote growth and development. Fish that are being raised as future breeders will benefit from use of other food items. While a dry diet may be used exclusively, the addition of live or frozen feeds such as blood worms (Glycera spp.), adult brine shrimp, tubifex worms (Tubifex spp.), or mosquito larvae (Culicidae), may improve egg and larval quality. There are many good dry commercial fish foods available for bettas once they are purchased by 
hobbyists, in addition to live and frozen options. However, proper storage and feeding regimens-avoiding overfeeding and water fouling-as well as clean sources of live feeds are very important considerations.

The term "biosecurity" refers to practices that minimize the risk of introducing an infectious disease to your fish and spreading it to other fish in the same or other tanks and systems (for a more advanced introduction, see USDA SRAC Publication \#4707 https://srac.tamu.edu/viewFactSheets). Biosecurity against the introduction of disease agents is simplified for betta males kept in individual tanks because they and their maintenance equipment are more isolated from other sources of potential disease.

Proper diagnostics will be facilitated by working with a fish veterinarian. Different possible causes of a disease outbreak (water quality, nutrition, infections) should be verified or ruled out to ensure more effective treatments. Many drugs and chemicals can do more harm than good if they are used inappropriately. To find a fish veterinarian, contact your local veterinarian, who may work with fish, or who may be able to recommend a colleague who does. You can also contact your state or local veterinary medical association, or search using the American Association of Fish Veterinarians locator button (fishvets.org).

\section{Summary and Conclusions}

The betta is one of the most popular and important freshwater aquarium species worldwide. It has an ancient history of production and use in Southeast Asia and is of considerable cultural significance. The fascinating evolutionary history of this species led to air-breathing and a robust physiology that allowed it to occupy shallow, warmer, low-oxygen environments and thrive where many other fishes could not survive. These natural adaptations make the betta highly suited to mass aquaculture production, especially grow-out in small, individual containers where many fish can be raised in a small "footprint." These adaptations also allow efficient and inexpensive global shipping from the main production centers in Southeast Asia to markets in the United States, Europe, Japan, and elsewhere. Wholesalers and retailers hold the males in an efficient and appropriate manner by using small containers while simultaneously managing water quality and fish health. Further, bettas can be maintained in a healthy, appropriate manner by aquarium hobbyists using small aquaria or fish bowls by likewise using good husbandry practices to maintain water quality and fish health. The evolutionary development, natural history, and domestication of this species makes it highly adapted to the common culture, shipping, and husbandry practices exhibited in today's global trade of bettas.

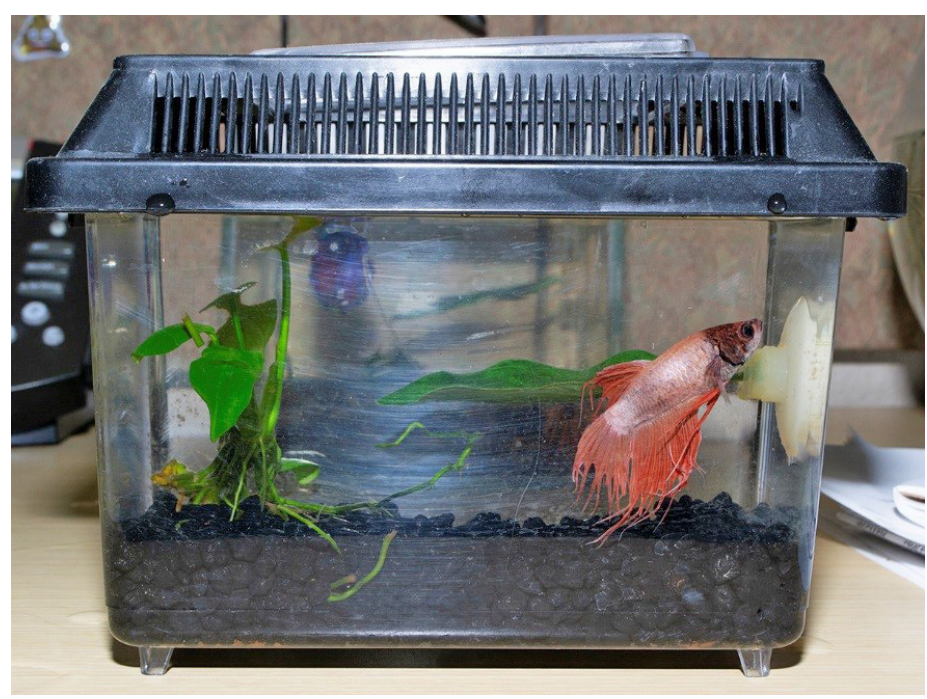

Figure 4. A male betta in a small aquarium.

Credits: Sandy Moore

\section{References}

Francis-Floyd, R. 2018. Stress-Its Role in Fish Disease. University of Florida Extension Circular 919. https://edis. ifas.ufl.edu/fa005.

Francis-Floyd, R., C. Watson, D. Petty, and D.B. Pouder. 2015. University of Florida Extension Circular FA16. https://edis.ifas.ufl.edu/fa031.

Graham, J. B. 1994. "An Evolutionary Perspective for Bimodal Respiration: A Biological Synthesis of Fish Air Breathing." American Zoologist 34:229-237.

Hurtado-Parrado, C., C. Acevedo-Triana, and J. Pearl. 2019. "Aversive Control of Betta splendens Behavior Using Water Disturbances: Effects of Signaled and Unsignaled FreeOperant Avoidance and Escape Contingencies." Behavioral Processes 158:18-31.

Jaroensutasinee, M and K. Jaroensutasinee. 2001. "Bubble Nest Habitat Characteristics of Wild Siamese Fighting Fish." Journal of Fish Biology 58:1311-1319.

Monvises, A., B. Nuangsaeng, N Sriwattanarothai, and B. Panijpan. 2009. "The Siamese Fighting Fish: Well-known Generally, but Little Known Scientifically." Science Asia 35:8-16.

Pleeging, C. C. F., and C. P. H. Moons. 2017. "Potential Welfare Issues of the Siamese Fighting Fish (Betta splendens) at the Retailer and Hobbyist Aquarium." Vlaams Diergeneeskundig Tijdschrift 86:213-223. 
Saekhow, S., K. Thongprajukaew, W. Phromkunthong, and H. Sae-Khoo. 2018. "Minimal Water Volume for Intensively Producing Male Siamese Fighting Fish (Betta splendens Regan, 1910)." Fish Physiology and Biochemistry 44:1075-1085.

Tate, M., R. McGoran, C. White, and S. Portugal. 2017. "Life in a Bubble: the Role of the Labyrinth Organ in Determining Territory, Mating and Aggressive Behaviors in Anabantoids." Journal of Fish Biology 91:723-749.

Yanong, R.P.E. and C. Erlacher-Reid. 2012. USDA Southern Regional Aquaculture Center (SRAC) Publication No. 4707. https://srac.tamu.edu/viewFactSheets. 